\title{
Measurement of the Division of Lightning Return Stroke Current Among the Multiple Arresters and Grounds of a Power Distribution Line
}

\author{
Carlos T. Mata, Member, IEEE, Vladimir A. Rakov, Fellow, IEEE, Keith J. Rambo, Pepe Diaz, Raimundo Rey, and \\ Martin A. Uman, Fellow, IEEE
}

\begin{abstract}
A triggered-lightning experiment was conducted during Summer 2000 at the International Center for Lightning Research and Testing (ICLRT) in north-central Florida for the purpose of studying the lightning current division in an 829-m-long, 18-pole, three-phase plus neutral, unenergized, overhead distribution line equipped with six arrester stations. Eight lightning flashes containing a total of 34 recorded return strokes, as well as low amplitude, long duration steady currents, were artificially initiated (triggered) from natural thunderclouds using the rocket-and-wire technique, and the flash currents were directed to phase $\mathrm{C}$ (one of the two outer conductors of the three-phase cross-arm-configured line). Six of the eight triggered lightning flashes caused damage to one of the two closest phase $\mathrm{C}$ arresters. In the case when no arrester was damaged or was not yet damaged by current in the flash, it is inferred that about $\mathbf{4 0 \%}$ of the return stroke peak current and about $25 \%$ or more of the return stroke charge transferred in the first millisecond passed to the neutral conductor through each of the two closest arresters located about $70 \mathrm{~m}$ away on either side of the strike point. The bulk of the peak current then flowed from the neutral conductor to ground through the groundings of the two closest arresters. The charge transferred in the first millisecond from the neutral to the eight system groundings, six at arrester stations, and one at each of the two line-end poles, appears to be distributed inversely to the low-frequency, low-current grounding resistances. From our measurements of return stroke current division and in view of the available data on the currents of first strokes in natural lightning, we estimate that over half of natural first strokes would result in an arrester failure in our test distribution line, which is representative of some distribution lines in service, within about $450 \mu \mathrm{s}$ of the initiation of the first return stroke current flow, in the absence of flashovers and other alternative current paths that might be provided by transformers or underground cable connections to allow the stroke current to bypass the arrester. Additional first stroke current flow beyond about $450 \mu$ s and currents associated with subsequent strokes and potentially other processes should further increase the likelihood of arrester damage.
\end{abstract}

Index Terms-Grounding electrodes, lightning, MOV arresters, power distribution lines.

Manuscript received March 27, 2002. This work was supported by Florida Power and Light.

C. T. Mata is with the Dynacs, Inc., Kennedy Space Center, FL 32899 USA (e-mail: cm@ieee.org).

V. A. Rakov, K. J. Rambo, and M. A. Uman are with the Department of Electrical and Compuetr Engineering, University of Florida, Gainesville, FL 32611 USA (e-mail: rakov@ece.ufl.edu; rambo@tec.ufl.edu; uman@ece.ufl.edu).

P. Diaz and R. Rey are with Florida Power and Light, Miami, FL 33174 USA (e-mail: Pepe_Diaz@fpl.com; Raimundo_Rey@fpl.com).

Digital Object Identifier 10.1109/TPWRD.2003.817541

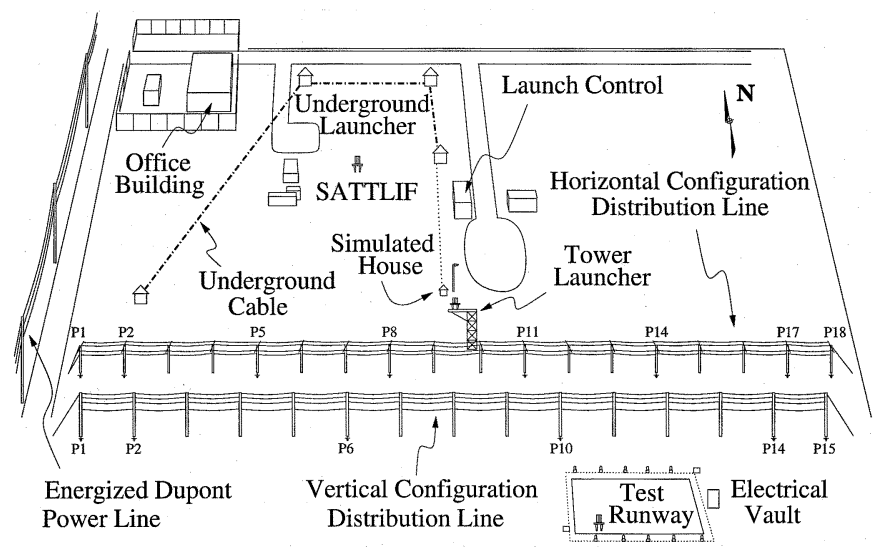

Fig. 1. Overview of the International Center for Lightning Research and Testing (ICLRT) at Camp Blanding, FL, Summer 2000.

\section{INTRODUCTION}

$\mathbf{T}$ HE International Center for Lightning Research and Testing (ICLRT) is located at Camp Blanding, FL, approximately midway between Gainesville and Jacksonville. The ICLRT is an outdoor facility that occupies about $1 \mathrm{~km}^{2}$ and is used for triggering lightning from natural overhead thunderclouds using the rocket-and-wire technique [1], [2]. An overview of the ICLRT facility during Summer 2000 is shown in Fig. 1 (see [3] for a detailed description of the ICLRT). The facility included an unenergized, four-conductor (three horizontally configured phase conductors plus a neutral conductor underneath), 829-m distribution line (Fig. 1). This distribution line is one of several standard distribution line configurations used by Florida Power and Light. The division of lightning current on the test line is the primary subject of this paper.

\section{EXPERIMENT}

The line was struck near the center of phase $\mathrm{C}$ with triggered flashes containing return strokes a total of eight times between July 11 and August 6, 2000. Six of these flashes produced damage to the phase $\mathrm{C}$ arrester at pole 8 at different times in the flashes. Of the two that did not, one had a rocket-trailing wire over the line and the other produced a phase-to-phase flashover at the current injection point. The eight triggered flashes contained 34 recorded return strokes. These return strokes were characterized by submicrosecond current risetimes and by peak currents having geometric and arithmetic means between 15 and $20 \mathrm{kA}$ with a maximum peak current of $56 \mathrm{kA}$. Each triggered 


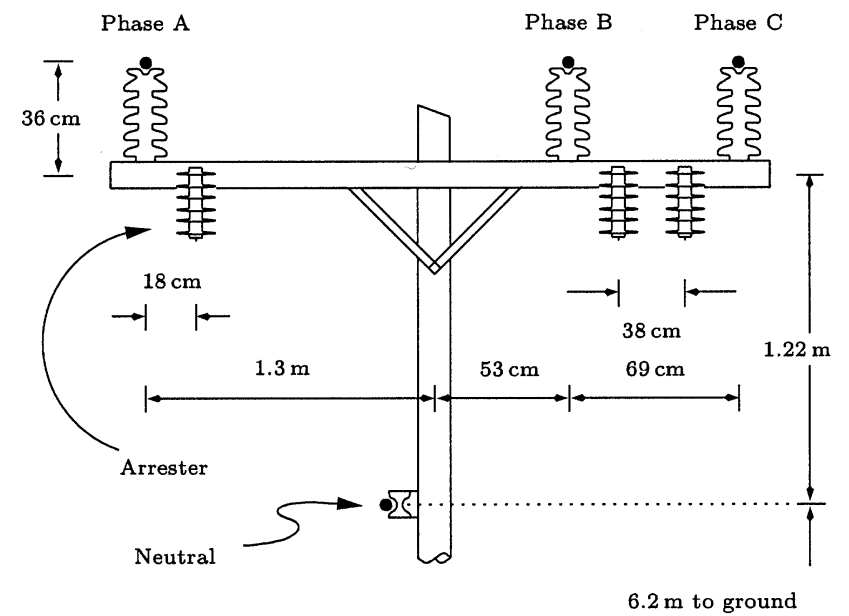

Fig. 2. Placement of conductors and arresters on the test distribution line.

flash also contained an initial continuous current of the order of hundreds of amperes, which flowed for a time of the order of hundreds of milliseconds, and some flashes contained a similar continuing current after subsequent strokes. The placement of conductors and arresters on the test distribution line is illustrated in Fig. 2. A total of six three-phase arrester stations were installed on the line, at poles $2,5,8,11,14$, and 17, the arresters being connected between the phase conductors and the neutral conductor. The neutral of the line was grounded at these poles and at the two line-terminating poles, 1 and 18 . The $829-\mathrm{m}$ three-phase line was terminated at each end in an impedance of about $500 \Omega$ via two $1000-\Omega, 1.75-\mathrm{MJ}$ resistors connected in parallel between the struck phase (phase C) and neutral, and a single $500-\Omega, 1.5-\mathrm{MJ}$ resistor connected between each of the other two phases and neutral. The distance between poles on the line varied from 47 to $73 \mathrm{~m}$. The grounding of the neutral at each arrester station pole and at the two terminating poles was accomplished by means of $24-\mathrm{m}$ vertically driven ground rods. The low-frequency, low-current grounding resistance of each pole ground was measured on several occasions using the fall-of-potential method. The measured grounding resistances on September 2000 were 41, 47, 28, 52, 55, 46, 37, and $22 \Omega$ for the ground rods at poles $1,2,5,8,11,14,17$, and 18 , respectively. Although the long-term variation of grounding resistance should be small, short-term variation can be significant due to sporadic rainfall in Florida, particularly during the summer months [4]. Two different brands of $18-\mathrm{kV}$ MOV arresters were used in the experiment: arresters installed at poles $2,5,14$, and 17 were from manufacturer " $\mathrm{A}$ " and those installed at poles 8 and 11 were from manufacturer "B." Polymer insulators were used at the terminating poles and ceramic insulators on all other poles, all $35 \mathrm{kV}$ rated. The $\mathrm{V}$-I characteristics of the $18-\mathrm{kV}$ arresters are shown in Table I. Arrester currents, line currents, neutral currents, and currents through the terminating resistor at pole 1 were measured with current transformers (CTs), and at each pole ground location with $1-\mathrm{m} \Omega$ current viewing resistors (shunts). Arrester voltages were measured with specially designed voltage dividers that were compensated for the additional voltages due to the time-varying magnetic flux produced by the arrester current and coupled to the voltage divider loop.
TABLE I

V-I CHARACTERISTICS OF THE $18-\mathrm{kV}$ MOV ARRESTERS OF TWO MANUFACTURERS

\begin{tabular}{c|c|c|c}
\hline \hline \multicolumn{2}{c|}{ Manufacturer "A" } & \multicolumn{2}{c}{ Manufacturer "B" } \\
\hline $\begin{array}{c}\text { Voltage } \\
{[\mathrm{kV}]}\end{array}$ & $\begin{array}{c}\text { Current } \\
{[\mathrm{kA}]}\end{array}$ & $\begin{array}{c}\text { Voltage } \\
{[\mathrm{kV}]}\end{array}$ & $\begin{array}{c}\text { Current } \\
{[\mathrm{kA}]}\end{array}$ \\
\hline \hline 48.5 & 1.5 & 49 & 1.5 \\
\hline 51.6 & 3 & 52 & 3 \\
\hline 53.9 & 5 & 55 & 5 \\
\hline 58.8 & 10 & 60 & 10 \\
\hline 65.0 & 20 & 70 & 20 \\
\hline 73.2 & 40 & 82 & 40 \\
\hline \hline
\end{tabular}

The voltage and current signals were recorded on LeCroy digitizing oscilloscopes at a sampling rate of $20 \mathrm{MHz}$. The total triggered-lightning current was measured at the rocket launching unit with a 1-m $\Omega$ shunt and recorded with a LeCroy digitizing oscilloscope having a sampling rate of $25 \mathrm{MHz}$. The oscilloscopes were housed in the launch control trailer (Fig. 1), and the sensor output signals were transmitted via Nicolet Isobe 3000 fiber optic links having a 15-MHz upper frequency response, each system being composed of an Isobe transmitter, a fiber optic cable, and an Isobe receiver. The upper frequency limits of the various current and voltage measurements were between 5 and $10 \mathrm{MHz}$, determined by the individual CTs, shunts, or voltage dividers. We estimate the potential error in making any given current or voltage measurement as $15 \%$.

\section{RESULTS}

Although there is a great deal of information that can be gleaned from the Summer 2000 experiments on the test distribution line, we focus here primarily on one aspect of those experiments: the paths of return stroke current from the strike point on one phase, $\mathrm{C}$, in the middle of the line, between poles 9 and 10, to the eight grounds. We study this division in detail for the five strokes of one flash, flash 0036. During those five strokes, arrester failure did not occur. We examine the return stroke peak currents and the charge transferred from the start of each of the return strokes to a time of $1 \mathrm{~ms}$. Additionally, we summarize in Fig. 6, the peak current distribution among the line grounds for all measured return strokes in all recorded flashes. In flash 0036, an initial continuous current and the currents of the first five recorded return strokes were injected into phase $\mathrm{C}$ between poles 9 and 10 prior to arrester failure at pole 8 . The arrester on pole 8 failed following the fifth stroke, perhaps from the accumulation of energy from the initial continuous current and the five strokes, or from those currents, any unrecorded continuing current between strokes, any unrecorded continuing current following the fifth stroke, and the currents of any additional unrecorded strokes. As an example, Fig. 3 shows a drawing depicting the division of the incident current for the first stroke of flash 0036. This stroke had a peak current of about $26 \mathrm{kA}$. Note that the arrester current at pole 8 was lost due to instrumentation (fiber optic link) malfunction, but it likely was similar to the arrester current at pole 11, given the symmetry of the other currents on the line. Also, no current was measured through the terminating resistor at pole 18 but that current was 


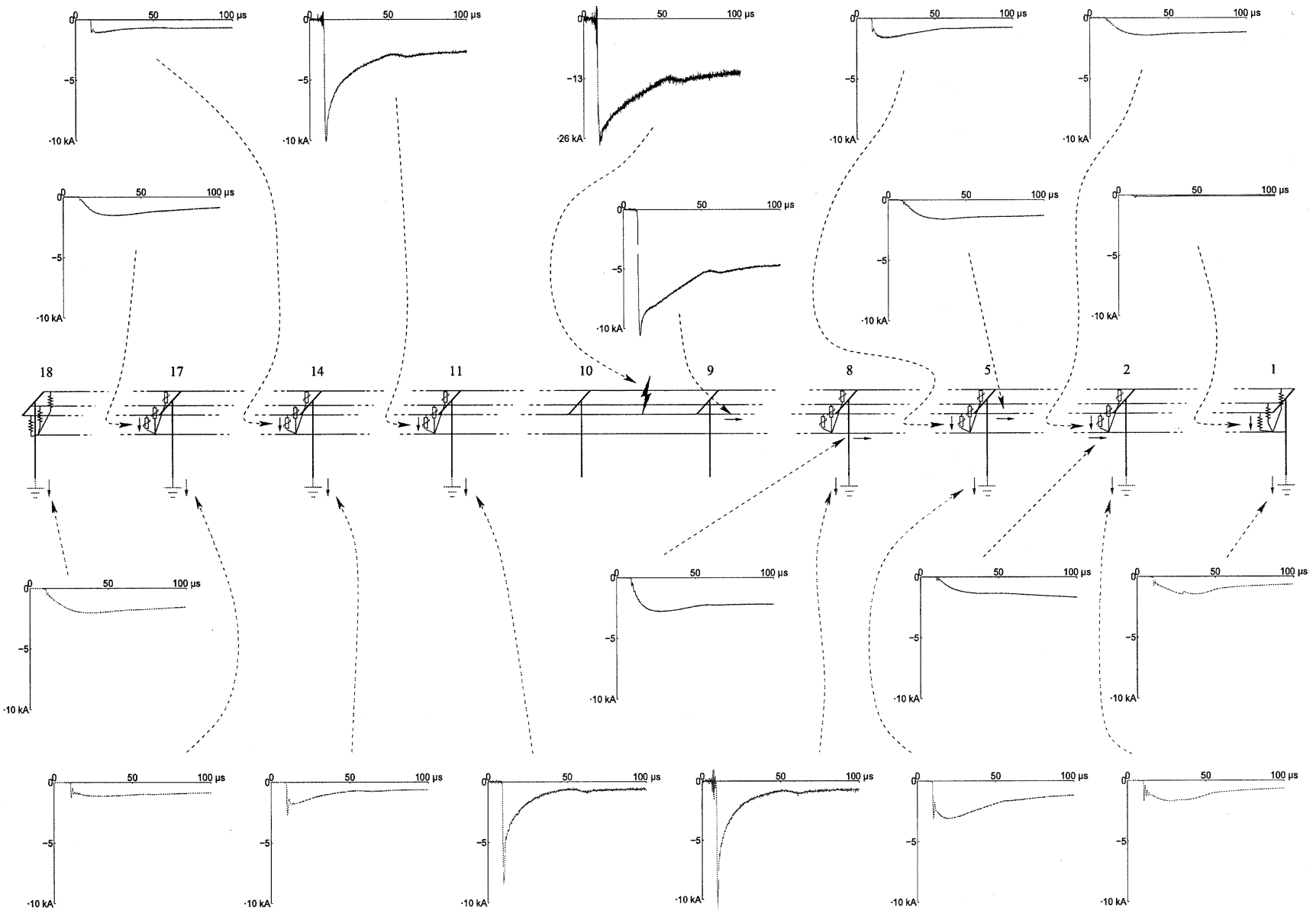

Fig. 3. Current distribution for flash 0036, stroke 1.

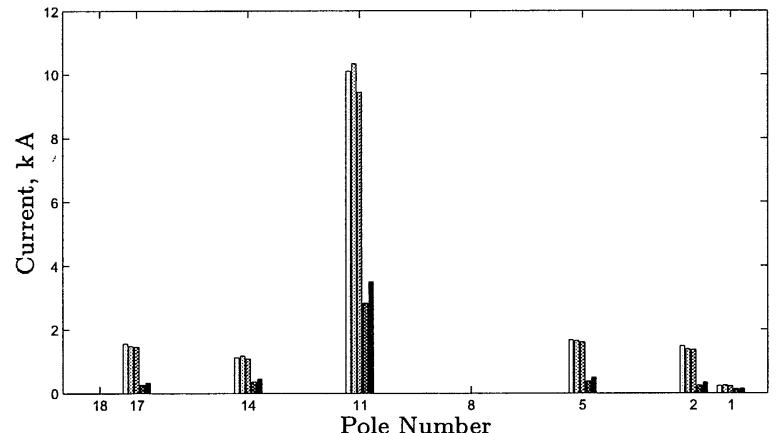

Fig. 4. Measured peak currents through arresters and terminating resistor at pole 1 for strokes 1 through 5 (in ascending order from left to right) of flash 0036.

likely relatively small and similar to the current that was measured through the terminating resistor at pole 1. Fig. 4 shows the arrester and terminator peak currents recorded for all five strokes of flash 0036, while Fig. 5 gives the peak currents entering all eight pole grounds for the five return strokes. It is evident from Figs. 3-5 that the bulk (about 80\%) of the peak current injected into phase $\mathrm{C}$ passed through the two phase $\mathrm{C}$ arresters, at pole 11 and by inference at pole 8 , and also went to ground at poles 8 and 11, even though the neutral was available to disperse the peak current to the other six grounds of the system. Fig. 6 shows the measured distribution of peak current

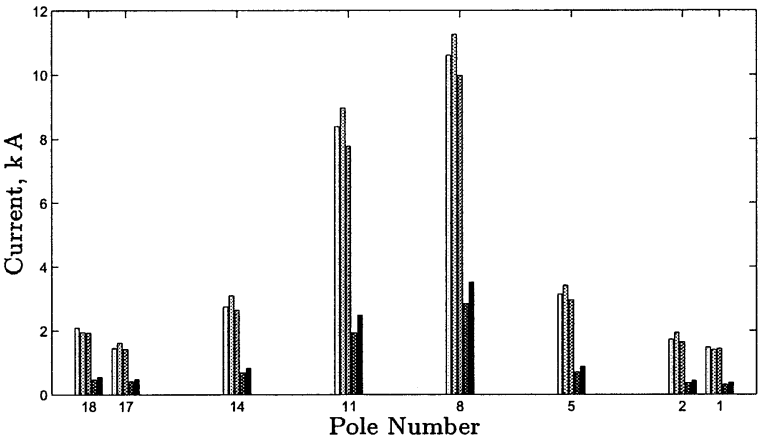

Fig. 5. Measured peak currents to ground for strokes 1 through 5 (in ascending order from left to right) of flash 0036.

to ground for all strokes triggered. In many of these events, there were flashovers and failed arresters on the line. It is evident that all strokes show a behavior similar to that in the example above from flash 0036, stroke 1. Fig. 3 shows current waveforms only to $100 \mu \mathrm{s}$. Nevertheless, incident charge, and hence, incident current, continued to flow in the system at least until $1 \mathrm{~ms}$ (see Fig. 7 and 8). Since the recorded currents decayed to the measuring system noise level (roughly $\pm 200 \mathrm{~A}$ ) within about $1 \mathrm{~ms}$ (the total recording window was $10 \mathrm{~ms}$ ), the division of current after $1 \mathrm{~ms}$ is not known. As follows from Fig. 7, about $25 \%$ of the charge flows through each of the two closest arresters on the struck phase, although this percentage may be an underestimate, 


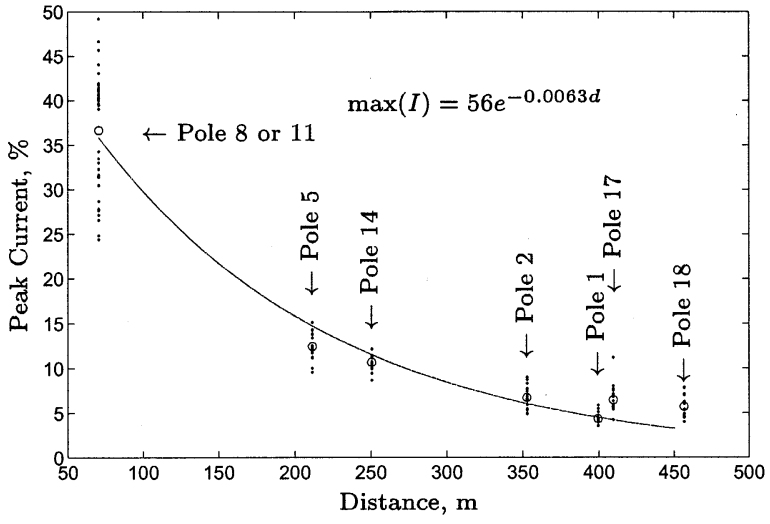

Fig. 6. Measured peak current to ground in percent of the total lightning peak current as a function of distance from the strike point. Dots represent measured peak current to ground for all strokes triggered in 2000 with no severe saturation, circles indicate mean values, and the solid line is the exponential function that fits the mean values.

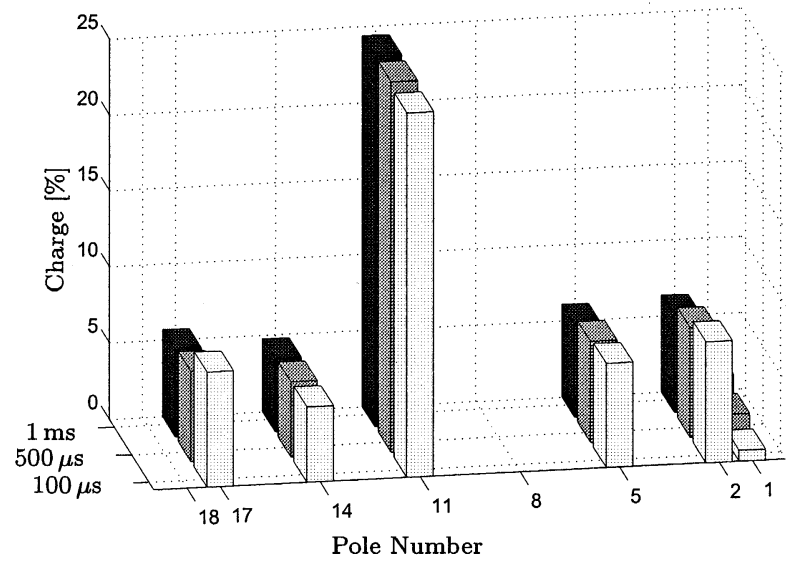

Fig. 7. Percentage of total charge transferred through phase $\mathrm{C}$ arresters at different poles and terminating resistor at pole 1 , calculated at three different instants of time $(100 \mu \mathrm{s}, 500 \mu \mathrm{s}$, and $1 \mathrm{~ms}$ from the beginning of the return stroke), for stroke 1 of flash 0036 . No measurements are available at pole 8 and pole 18 .

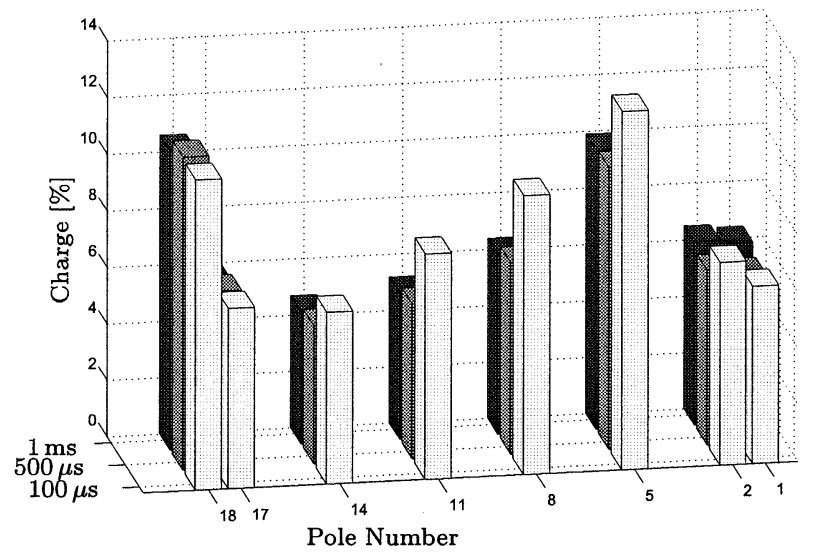

Fig. 8. Percentage of total charge transferred to ground at different poles, calculated at three different instants of time $(100 \mu \mathrm{s}, 500 \mu \mathrm{s}$, and $1 \mathrm{~ms}$ from the beginning of the return stroke), for stroke 1 of flash 0036 .

since the summed charge (transferred through all six arresters, assuming the charge transfer through the pole 8 arrester equals that through the pole 11 arrester, and one termination resistor) only adds up to about $70-75 \%$ (for all five strokes) of the inci- dent charge. The latter was calculated by integrating the current waveform measured at the rocket launcher. We were unable to identify any flashovers in our video records that might have accounted for the remaining $25-30 \%$ of the incident charge, but cannot rule out such flashovers. It is not possible to tell if the measured incident stroke current peaks are fully accounted for in the various peak current measurements because the current peaks occur at different times at different locations, and the current waveshapes also change with location on the line.

It is interesting to note from Fig. 3, an observation also illustrated in Fig. 8, that after $25 \mu \mathrm{s}$ or so, the current to ground no longer flows from the neutral primarily through the grounds closest to the strike point but is more uniformly distributed among the eight grounds. In fact, the currents after $25 \mu \mathrm{s}$ are distributed roughly inversely to the measured low frequency, low current ground resistance, with the largest current going to the $22-\Omega$ ground at pole 18 . Fig. 8 shows that the percentage of charge transferred to a given ground in the first $100 \mu \mathrm{s}$ is not much different from that transferred in the first millisecond.

\section{DISCUSSION}

Based on our observations that about $40 \%$ of the return stroke peak current and about $25 \%$ of the return stroke charge to $1 \mathrm{~ms}$ pass from the struck phase to the neutral through each of the two closest arresters of that phase, we are able to draw some inferences on the energy dissipation and likelihood of failure of those closest arresters for the case of both triggered and, by extrapolation, natural lightning strokes.

A typical maximum dissipation energy for MOV arresters is 4 $\mathrm{kJ}$ per kilovolt rated [5]. For our $18 \mathrm{~kJ}$-rated arresters, the typical expected withstand energy is therefore $72 \mathrm{~kJ}$. The exact value depends on the current waveshape and the V-I characteristics of the arrester (the latter being a function of the current waveshape). Typical published V-I characteristics are for $8 / 20-\mu \mathrm{s}$ waveforms. For triggered lightning, we have measured the energy (product of the measured current and measured voltage integrated over time) dissipated by an arrester at pole 8 during the initial continuous current of flash 0037 (triggered after flash 0036) that caused arrester failure after $25 \mathrm{~ms}$ of current in the tens of ampere to 100-A range [3]. The arrester failed from this relatively low-frequency current at a dissipated energy of $90 \mathrm{~kJ}$. Using the same technique, we found the total energy dissipated by the phase $\mathrm{C}$ arrester at pole 11 for the first five strokes of flash 0036, which did not cause arrester failure at either of the two closest arresters, to be approximately $84 \mathrm{~kJ}$. We assume that the energy dissipated by the arrester at pole 8 , where the measurement of the current was lost, was about the same as that at pole 11. An illustration of the initial $100 \mu \mathrm{s}$ of the stroke 1 current waveform of flash 0036 which dissipated $30 \mathrm{~kJ}$ at the pole 11 arrester in about $1 \mathrm{~ms}$ of current flow is shown in Fig. 3. For each of the five strokes of flash 0036, the current after $1 \mathrm{~ms}$ or so, if any, was indistinguishable from the system noise level (roughly $\pm 200 \mathrm{~A}$ ); and hence, the bulk of the charge passing through the arresters apparently did so in the first $100 \mu \mathrm{s}$ or so, as is evident from Fig. 7, unless an undetected current below the system noise level persisted for many tens of milliseconds. As noted earlier, the pole 8 arrester failed following the five strokes 


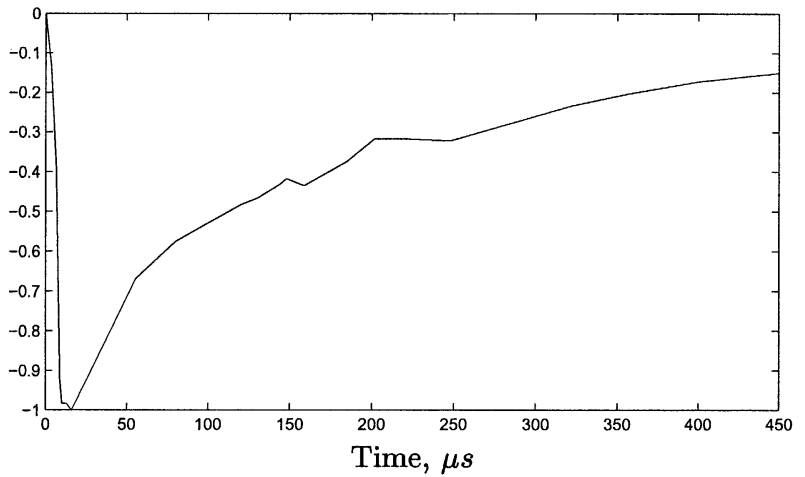

Fig. 9. Averaged first stroke current waveform from natural lightning normalized so that its peak is equal to unity. Adapted from Berger et al. (1975).

of flash 0036. We did not record the energy dissipation associated with the initial continuous current of flash 0036, any continuing current near \pm 200 A that may have occurred between strokes, or the event or events after stroke 5 that was followed by the failure. Thus, it appears that the arrester energy for this sequence of impulse currents (note that there may have been some arrester cooling between strokes) exceeded $84 \mathrm{~kJ}$.

We have estimated the energy delivered to the pole 11 and by inferrence pole 8 arresters by the five strokes of flash 0036 using two methods: (1) from the measured current and voltage waveforms integrated over time (the technique discussed in the previous paragraph), and (2) from the measured current waveform and a voltage waveform determined from the published V-I characteristic of the arrester (Table I, manufacturer "B"), the V-I characteristic being presumably obtained for an $8 / 20-\mu \mathrm{s}$ waveform. The values determined the two different ways are in reasonable agreement, at least for the larger energy inputs. For method (1)/ (2) and stroke $1,30 \mathrm{~kJ} / 39 \mathrm{~kJ}$; stroke $2,30 \mathrm{~kJ} / 35 \mathrm{~kJ}$; stroke $3,19 \mathrm{~kJ} / 20 \mathrm{~kJ}$; stroke $4,2.7 \mathrm{~kJ} / 1.5 \mathrm{~kJ}$; and stroke $5,3.1$ $\mathrm{KJ} / 2.1 \mathrm{~kJ}$. Assuming that this reasonable agreement would hold for first strokes in natural lightning and using a knowledge of natural first stroke currents, we can estimate the energy delivered to a close arrester on a line similar to our test line by a natural first stroke. Berger et al. (1975) averaged about 100 first stroke current waveforms to arrive at the average current waveform shown in Fig. 9. The peak current in Fig. 9 is normalized to unity and the waveform extends to $450 \mu \mathrm{s}$ at which point the current has decreased to about $15 \%$ of peak value. If we multiply the current waveform of Fig. 9 by the voltage waveform derived from the same V-I characteristic used for calculating the energy dissipated for the strokes in triggered flash 0036 and integrate to $450 \mu \mathrm{s}$ (method (2) above), we find the resultant arrester dissipated energy plotted in Fig. 10 as a function of peak stroke current versus percent of that total current going through each of the two closest arresters. For example, if we assume conservatively (based on our measurements) that $25 \%$ of the current goes through one arrester and that the first stroke peak current is the median value found by Berger et al. (1975) of about 30 $\mathrm{kA}$, about $70 \mathrm{~kJ}$ is dissipated in the arrester, an energy near the nominal failure value. Since the tail (beyond the $450 \mu$ s depicted by Berger et al. 1975) of the first stroke waveform will further increase the dissipated energy, it follows that over half of first

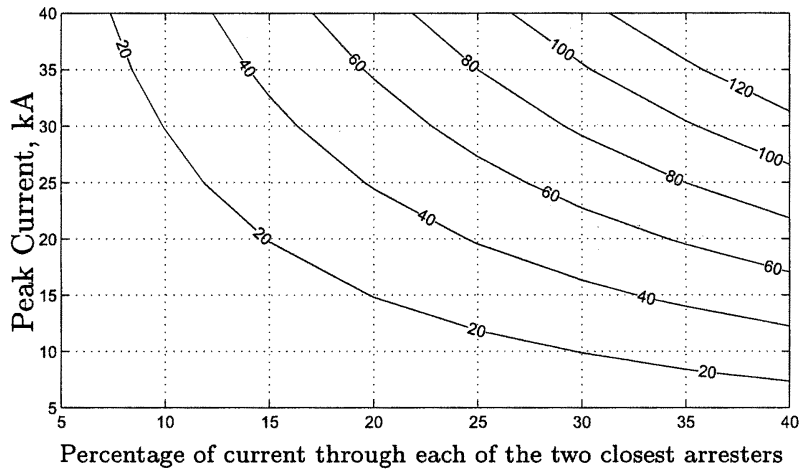

Fig. 10. Arrester dissipated energy in kilojoules as a function of peak current for the fixed current waveform shown in Fig. 9 and the percent of total lightning current through the arrester about $70 \mathrm{~m}$ from the strike point in the absence of flashovers and other alternate paths for current to bypass the arrester.

strokes should cause failure to the closest arrester in the absence of processes such as flashover and alternate paths such as transformers or underground cable connections that can allow current to bypass the arrester. Further, since the energy delivered by natural subsequent strokes (similar to all strokes in triggered lightning) and any continuing current flowing through the arrester must be added to the first stroke energy, although some cooling may occur between strokes, the fraction of close arrester failures should be even larger. The typical number of strokes in natural negative flashes is 3 to 5 .

In the triggered lightning experiments discussed in this paper, most of the return stroke charge transfer that was observed above the system noise level of about \pm 200 A was via the impulse currents of return strokes. Our future experiments will be aimed at both accumulating more data on the current division of impulsive current components and at determining the current division of the low level (order of $100 \mathrm{~A}$ ), long duration (tens to hundreds of milliseconds) continuing currents that follow individual strokes in about half of natural flashes [7]. If a significant fraction of the continuing current, associated with a typical charge transfer of $10 \mathrm{C}$ [7], flows through the nearest two arresters, as opposed to being divided among many arresters, then the stress to the nearest arresters will be increased significantly above the estimates given in the previous paragraph. It would then follow that, in the absence of flashover or other alternate paths for current flow to ground such as through transformer windings, one of the two closest arresters will likely fail in the case of natural lightning strikes to the line.

\section{ACKNOWLEDGMENT}

We wish to thank the following individuals who participated in the experiment: M. Stapleton, A. Mata, R. Sutil, G. Bronsted, and G. Schnetzer.

\section{REFERENCES}

[1] M. A. Uman, V. A. Rakov, K. J. Rambo, T. W. Vaught, M. I. Fernandez, D. J. Cordier, R. M. Chandler, R. Bernstein, and C. Golden, "Triggeredlightning experiments at Camp Blanding, Florida (1993-1995)," Trans. Inst. Elect. Eng. Jap., Special Issue on Artificial Rocket Triggered Lightning, vol. 117-B, no. 4, pp. 446-452, 1997. 
[2] V. A. Rakov, M. A. Uman, K. J. Rambo, M. I. Fernandez, R. J. Fisher, G. H. Schnetzer, R. Tottappillil, A. Eybert-Berard, J. P. Berlandis, P. Lalande, A. Bonamy, P. Laroche, and A. Bondiou-Clergerie, "New insights into lightning processes gained from triggered-lightning experiments in Florida and Alabama," J. Geophys. Res., vol. 103, pp. 14 117-14 130, 1998.

[3] C. T. Mata, "Interaction of Lightning With Power Distribution Lines," Ph.D. dissertation, Univ. Florida, Gainesville, FL, Dec. 2000.

[4] M. I. Fernandez, C. T. Mata, V. A. Rakov, M. A. Uman, K. J. Rambo, M. V. Stapleton, and M. Bejleri, "Improved Lightning Arrester Protection Results, Final Results,” Electric Power Research Institute, Palo Alto, CA, Tech. Rep. TR-109670-R1, Dec. 1998.

[5] A. Greenwood, Electrical Transients in Power Systems, 2nd ed. New York: Wiley, 1991.

[6] K. Berger, R. B. Anderson, and H. Kroninger, "Parameters of lightning flashes," Electra, no. 41, pp. 23-27, July 1975.

[7] M. A. Uman, The Lightning Discharge. New York: Academic, 1987.

Carlos T. Mata (M'01) received the Bachelor's degree from the "Universidad Simón Bolívar" (USB), Venezuela, in 1993, and the Master's and Ph.D. degrees from the University of Florida (UF), Gainesville, in 1997 and 2000, respectively.

Currently, he is with Kennedy Space Center, FL, doing embedded system and advanced data acquisition systems design in support to the Shuttle program. He is involved in the area of computer modeling of different lightning processes and responses of power distribution systems to direct and nearby lightning strikes. $\mathrm{He}$ is author or co-author of several journal publications and technical reports.

Dr. Mata is a member of the American Geophysical Union (AGU), the Power Engineering Society (PES), and the Instrumentation, Systems, and Automation Society (ISA). In 1998, Dr. Mata received the GAANN fellowship and in 2001 the IEEE Power Engineering Society SPDC Prize Paper Award and Innovative Excellence Award at the Kennedy Space Center, FL.

Vladimir A. Rakov (SM'96-F'03) received the Master's and Ph.D. degrees from Tomsk Polytechnical University (Tomsk Polytechnic), Tomsk, Russia, in 1977 and 1983, respectively.

Currently, he is Professor of the University of Florida's (UF) Department of Electrical and Computer Engineering. He was an Assistant Professor of Electrical Engineering at Tomsk Polytechnic from 1977 to 1979. In 1978, he became involved in lightning research at the High Voltage Research Institute, a division of Tomsk Polytechnic, where from 1984 to 1994, he held the position of Director of the Lightning Research Laboratory. In 1985, he received the rank of Senior Scientist in High Voltage Engineering. In 1991, he joined the faculty of the Department of Electrical and Computer Engineering at UF. He is the author or co-author of over 30 patents and many papers and technical reports on various aspects of lightning, with many papers being published in reviewed journals

Dr. Rakov has been named an Inventor of the USSR in 1986, and received a Silver Medal from the (USSR) National Exhibition of Technological Achievements in 1987. Dr. Rakov is Chairman of the Technical Committee on Lightning of the biennial International Zurich Symposium on Electromagnetic Compatibility and of the AGU Committee on Atmospheric and Space Electricity.
Keith J. Rambo received the B.S.E.E. degree from the University of Florida (UF), Gainesville, in 1978 .

Currently, he is Director of Technical Support Services at the UF Department of Electrical and Computer Engineering, where he has been since 1986. Since 1994, he has been heavily involved in triggered-lightning experiments at Camp Blanding, FL. As an undergraduate, he worked in the UF Lightning Research Laboratory, Gainesville, FL. From 1979 to 1983, he was Senior Process Development Engineer at Intel Corporation, Santa Clara, CA. From 1983 through 1986, he was a Product Line Manager for Xicor, Milpitas, CA, responsible for all aspects of wafer fabrication. He has been published in several technical publications.

Pepe Diaz, photograph and biography not available at the time of publication.
Raimundo Rey is a Principal Engineer with Florida Power and Light, Miami, FL. His current responsibilities include the origination and coordination of research and development projects to improve the reliability of power delivery systems. He has also worked extensively in the areas of system planning and resource optimization, including generation/transmission expansion planning, dynamic stability analysis, as well as the analysis of power systems under fault conditions. He is the author of several technical papers and reports on issues related to power system planning and control.

Martin A. Uman (F'88) received the Ph.D. degree from Princeton University, Princeton, NJ, in 1961.

Currently, he is Distinguished Professor of the University of Florida's Department of Electrical and Computer Engineering, Gainesville, FL. He was an Associate Professor of Electrical Engineering at the University of Arizona, Tucson, from 1961 to 1964. Dr. Uman joined the University of Florida faculty in 1971 after working for seven years as a Fellow Physicist at Westinghouse Research Labs, Pittsburgh, PA. Dr. Uman co-founded and served as President of Lightning Location and Protection, Inc. (LLP) from 1975 to 1985 . He has written four books on the subject of lightning, as well as a book on plasma physics, ten book chapters, and encyclopedia articles on lightning, and has published many papers in reviewed journals. He holds five patents, four in the area of lightning detection.

Dr. Uman is a Fellow in three professional organizations: the American Geophysical Union (AGU), the American Meteorological Society (AMS), and the Institute of Electrical and Electronics Engineers. Dr. Uman is the recipient of the 1996 IEEE Heinrich Hertz Medal for "outstanding contributions to the understanding of lightning electromagnetics and its application to lightning detection and protection" and the 2001 AGU John Adam Fleming Medal for original research and technical leadership in geomagnetism, atmospheric electricity, space science, aeronomy, and related sciences: "for outstanding contribution to the description and understanding of electricity and magnetism of the Earth and its atmosphere." 